This item was submitted to Loughborough's Research Repository by the author.

Items in Figshare are protected by copyright, with all rights reserved, unless otherwise indicated.

\title{
Feedback device for improvement of coordination of reach-to-grasp after stroke
}

PLEASE CITE THE PUBLISHED VERSION

http://dx.doi.org/10.1016/j.apmr.2011.07.204

\section{PUBLISHER}

Elsevier / ( A American Congress of Rehabilitation Medicine

VERSION

SMUR (Submitted Manuscript Under Review)

\section{PUBLISHER STATEMENT}

This work is made available according to the conditions of the Creative Commons Attribution-NonCommercialNoDerivatives 4.0 International (CC BY-NC-ND 4.0) licence. Full details of this licence are available at: https://creativecommons.org/licenses/by-nc-nd/4.0/

\section{LICENCE}

CC BY-NC-ND 4.0

\section{REPOSITORY RECORD}

van Vliet, Paulette M., Andrew Wimperis, James Creak, Andrew J. Taylor, and Cees van der Eijk. 2019. "Feedback Device for Improvement of Coordination of Reach-to-grasp After Stroke". figshare. https://hdl.handle.net/2134/15691. 


\section{Title Page}

Title: Feedback device for improvement of coordination of reach-to-grasp following stroke

Word count: 4,417

Figures: 3

Tables: 2

This study was supported by a Mercia Spinner Pathfinder grant. 


\section{$\underline{\text { Abstract }}$}

\section{Objective}

To investigate the perceived utility, usability and usefulness and the effectiveness of a feedback device (GRASP) that displays time delay between start of hand movement towards an object and start of hand opening.

\section{Design}

There were two investigations comprising user trials and multiple baseline single case studies.

Initial prototype testing on two participants identified key adjustments. Four therapists and five participants with stroke then trialled the prototype and completed questionnaires. Single case studies used a multiple baseline across subjects design. A single baseline phase was followed by a single intervention phase, each subject performing forty repetitions of reaching to grasp a jar. Two subjects underwent each baseline phase. Random assignment to baseline phase was used.

\section{Setting}

A physiotherapy department or the participant's home.

\section{Participants}


A consecutive sample of seven stroke participants were recruited from the community setting for user trials. Inclusion criteria were middle cerebral artery or parietal stroke and a Rivermead Motor Assessment score of 6 or more.

Six further participants took part in the case studies, with additional inclusion criteria of time between start of hand opening and transport more than $60 \mathrm{~ms}$.

\section{Interventions}

Blocked practice of a reach-to-grasp task was performed while feedback was provided to participants with GRASP.

\section{Main outcome measures}

The outcome measure in the single case studies was time between start of transport and start of grasp.

\section{Results}

User trial results supported the utility, usability, usefulness and value of GRASP. Case studies indicated a significant decrease in time delay between start of transport and grasp.

\section{Conclusions}

This pilot investigation indicates that GRASP is a potentially useful adjunct to physiotherapy after stroke.

\section{Key words}


Stroke, Physical Therapy, Feedback, Equipment and Supplies 


\section{INTRODUCTION}

Impairments of upper limb movements after stroke are often persistent and disabling, with only $20 \%{ }^{1}$ to $56 \%{ }^{2}$ of participants regaining useful upper limb function after three months. New technologies to assist more people to regain useful arm movement following stroke would therefore have major benefits. An important motor impairment resulting from stroke is a lack of coordination between arm and hand ${ }^{3}{ }^{4}$. This report evaluates a feedback device that can be used to improve the coordination of arm and hand at the beginning of a reach-to-grasp movement.

In healthy subjects, for a given reach-to-grasp movement the hand follows a characteristic path and trajectory as it moves towards an object, described as the 'transport' component (change over time of the position of the wrist ${ }^{5}$ ) and the hand opens and closes on the object, the 'grasp' component (change over time of the distance between the index finger and thumb ${ }^{5}$ ). Neurophysiological evidence supports separate but interdependent visuomotor control channels for these two components ${ }^{6}$.

Transport and grasp must be coordinated to ensure that the object is grasped successfully. An invariant temporal relationship exists between the two components, where the start time of the hand opening is correlated with the start of hand movement towards the object 58 , and the time of maximum hand opening is correlated with the time of peak deceleration of the hand ${ }^{5910}$. Following stroke, two groups of participants have so far been identified as having difficulties with this temporal coordination of reach-to-grasp compared to healthy subjects: those with lesions affecting the middle cerebral artery (MCA) and those with 
lesions to the cerebellum. One study showed that participants with stroke affecting the territory of the MCA have less significant correlations between the above events compared to healthy participants, both at the start of the reach and at the time of maximum aperture ${ }^{3}$. In two further groups of patients with heterogenous stroke lesion sites, two patients did not begin their hand opening until near the end of the transport ${ }^{4}$ and there was an impaired ability to adjust timing of grasp for different sized objects ${ }^{11}$. Secondly, in a study of cerebellar participants ${ }^{12}$ the hand opened early and with more variable timing than healthy participants.

Having access to feedback about the time between the start of hand opening and the start of transport could be used to direct the participant's efforts to timing these events to start together, thereby inducing a more normal temporal coordination of reach-to-grasp. There are currently no feedback devices that perform this function for reach-to-grasp. However, other feedback devices used with stroke participants have been found to significantly improve motor performance, for example to encourage symmetrical weight bearing in standing up ${ }^{13}$, and for balance in sitting ${ }^{14}$.

The objectives of this report are to (a) describe a device called 'GRASP' - 'grasp rehabilitation accessory for stroke participants'- that gives feedback to both participant and therapist about the time lag between the start of hand opening and the start of the transport, (b) to report the results of user trials to assess its perceived utility, perceived usability and perceived usefulness from the point of view of both participant and therapist and (c) to report the results of a series of multiple baseline statistical analyses, designed to assess the effectiveness of the device for improving the coordination of arm and hand 
at the beginning of a reach-to-grasp movement. This study focused on a group of participants with middle cerebral artery stroke or parietal lobe damage because these kinds of participants were prevalent in a previous study demonstrating difficulties with coordination at the start of reach-to-grasp ${ }^{3}$ and the parietal cortex has been implicated in control of reach-to-grasp in several studies ${ }^{15} 16$.

\section{DEVICE DESCRIPTION}

The device comprises (1) sensors to detect the first and second body part movements; (2) a timer measuring the time lapsed between detection of the first and second movements; and (3) a user interface communicating the lapsed time to the participant and therapist.

Communication of the lapsed time enables instant feedback on the correlation of the two events and therefore on their coordination at the start of the movement. It also allows successive movements to be compared and the temporal order of the movements to be seen, i.e. whether the hand opened or moved forward first.

Both sensors are touch sensors comprising contact electrodes configured to monitor the electrical conductivity of a user's body through the skin surface. The hand sensor comprises a thumb electrode with a metallic outer surface such that placing a forefinger into contact initiates a grasp-closed condition. The wrist sensor comprises a metallic base plate configured to detect gross contact of a user's lower arm or wrist when at rest. A 
wristband worn on the other arm, holds the electrical potential of the user's body at a local system ground .

Onset of motion is detected by instant of loss of contact of either the thumb electrode or the wrist electrode. This triggers the start of timing. Subsequent loss of contact of the remaining electrode stops the timer and the resulting lapsed time is displayed to the user.

A system schematic diagram of GRASP is shown in Figure 1 and a photograph in Figure 2. The two electrodes and wristband are connected by leads to the control unit. The thumb electrode is a copper ring with an insulated plastic inner surface. Several sizes are available to comfortably fit over an adult thumb. The wrist electrode comprises a circular stainless steel base plate of a size to accommodate an adult user's wrist and hand when in a loose fist. The wristband is an elasticised bracelet of the type used widely in the electronics industry as a static grounding system. The materials are stainless steel and plastic and can be cleaned with alcohol or soapy water.

\section{INSERT FIGURE 1 ABOUT HERE}

INSERT FIGURE 2 ABOUT HERE

Any danger of electric shock is removed by using a low and isolated internal source voltage (12 V) complying with SELV as defined by IEE Regulations - 16 Edition. Such voltages are considered universally hazard free. A patent application has been published 17. 


\section{USER TRIALS}

\section{Participants}

Stroke participants were recruited consecutively from physiotherapy outpatient departments. Inclusion criteria were: middle cerebral artery or parietal stroke, and a score of 3 or more on the arm section of the Rivermead Motor Assessment (able to reach and pick up a tennis ball and release on thigh). Exclusion criteria were: cognitive dysfunction which prevented understanding of the task, severe concurrent medical problems that prevent repetitive reaching (including shoulder pain), or lack of informed consent. Seven participants with stroke took part. Significant problems can be identified using this method with this number of subjects, in user trials ${ }^{18}$. Four therapists who were providing routine care to the five stroke participants in the second stage of the user trials were also recruited. All testing took place in the location where they received their routine physiotherapy treatment, which was either in the inpatient or outpatient physiotherapy department, or at the participant's home. Approval was obtained for all procedures from the local Research Ethics Committee and from the Medicines and Healthcare products Regulatory Agency. The participant group (Table 1) consisted of 3 women and 4 men, with a mean age of 60.9 years (SD 16.95) and time since event causing brain damage was 19.7 months (SD 13.4). To describe the participant group in more detail, the following assessments were performed: arm section of the Rivermead Motor Asessment ${ }^{19}$, Modified Ashworth scale (muscle tone) ${ }^{20}$, star cancellation (neglect), Rey figure copy (spatial perception) ${ }^{21}$, Arm Position Matching test (proprioception) ${ }^{22}$, Nottingham Sensory Assessment (proprioception in single case studies) and a test for optic ataxia 
adapted from the 'reaching for an object' test described by Perenin ${ }^{23}$ (Table 1). None had receptive or expressive communication difficulties. In summary, the group had a moderate degree of arm impairment, no loss of proprioception, minor increases in muscle tone and several participants had neglect, optic ataxia, and impairments of spatial perception.

\section{Design}

The study design comprised an iterative investigation with two stages to allow scope for the prototype to be modified in response to the research findings. Initially the prototype was tested by the researcher on two participants with stroke, followed by a semistructured interview with the participants. Adjustments to the device were made, based on the findings. In the second stage four therapists and five participants with stroke used the adjusted prototype and then completed a questionnaire.

\section{Procedure: Stage One}

One researcher conducted the first two testing sessions and semi-structured interviews. The practice session lasted for 30 minutes, with GRASP used to provide feedback to the participant to improve synchronization of the start of movement and the start of hand opening. Blocked practice of reach-to-grasp was used, and practice of the task was varied by altering size of object, direction, speed, or height of the movement as appropriate. The participant was informed about: (a) the time lag between the start of transport and start of grasp, by directing the participant's attention to the timer display after each attempt, and (b) which component occurred first. 
A semi-structured interview with the participant was conducted immediately after the practice and was tape recorded. The topics included: (a) usability: how easy it was to put on and use the device, how comfortable it was, how easy it was to read the time display, and whether the participant had any concerns about using it; (b) utility: "The device is supposed to make the hand opening and the movement forward happen at approximately the same time. In your opinion, does the device do this?”; (c) usefulness: whether the participant thought that using the device had any effect and what these effects were, whether they thought that either moving the hand forward, opening the hand or coordination of these two were improved by using the device, and whether extra value had been added to the usual physiotherapy treatment.

Interviews were transcribed verbatim and categories identified from the data grouped into themes. The researcher and the device manufacturer conferred on the themes until agreement was reached regarding changes to the device. Some minor adjustments to the device were made after the first two participants had been tested (reported in results).

\section{Procedure: Stage Two}

Therapists were given a short training session on set up and use of the device and were provided with instructions. Then, the device was put on once and the stroke participant performed blocked practice of reach-to-grasp for 30 minutes. In order to resemble how the device would be used in routine clinical practice, the therapist was allowed to use their clinical judgement to vary the task by altering size of object, direction, speed, or 
height of the movement as appropriate, and to decide on the number of repetitions to be performed. The therapist and participant completed separate questionnaires after practice, without the researcher being present.

The questions were the same as in the interview conducted with the first two participants with the following additional questions included in the therapist questionnaire: "How useful is it to have a measurement of the time between the start of hand opening and the start of hand movement forward?” and “Does using the device improve your ability to give feedback to participants about arm coordination?” A combination of open and closed questions was used.

\section{Data analysis}

Results from all seven stroke participants were combined. Numbers of responses to each question were reported, with examples of answers to open questions.

\section{RESULTS}

\section{Results of Interviews}

The interviews showed that none of the participants had concerns about using GRASP. Participant 1 found it easy to put on and use, but the other less able participant 2 found the wires interfered with movement and suggested an improved fit of the thumb piece. He needed assistance to place the fingertip on the thumb electrode and to maintain that position. Neither participant felt able to comment on whether the device had improved 
the ability to make the hand opening and forward movement happen at the same time. Participant 1 felt that it would have been more useful earlier after his stroke, when he had a limited and delayed opening of the hand. Following the interviews, the following changes were made to GRASP. The wire between the wrist band and wrist plate was lengthened to avoid interference with reaching. In addition a set of instructions for therapists using GRASP was written which included: 1) placing of components so as not to interfere with reaching movements 2) photographs for ideal set-up for left and right hand use 3) selecting the correct size of thumb piece and 4) instructions to perform blocked practice of reach-to-grasp incorporating variation of the task by altering size of object, direction, speed, or height of the movement as appropriate.

\section{Results of questionnaires}

Perceived Usability: Four participants reported that the GRASP was easy to put on and four out of five participants reported that it was easy to use. Participant 6 found it difficult to use because she could not easily position the finger to obtain the finger-thumb contact necessary to trigger the recording of the device. All participants reported that it was comfortable to wear and all found it easy to see the digital time display. No one reported any concerns about using GRASP. All therapists found it easy to put on the device and to see the digital display. The therapist treating participant 6 noted the difficulty in opposing the finger to the thumb consistently, therefore delaying each trial. Perceived Utility 
All participants and therapists thought that the GRASP did fulfil its purpose of encouraging the hand opening and the forward movement of the hand to happen at approximately the same time.

\section{Perceived usefulness}

In answer to the question asking whether it had improved specific aspects of reach-tograsp, three participants answered that GRASP improved their coordination and moving their hand forward, and two participants that it improved their hand opening. Participant 5 found it helped to quicken her reach. When asked if GRASP added extra value compared to the usual physiotherapy treatment, all participants answered yes, with the following comments: "It gives encouragement to move your hand faster”, “Gives good quality feedback on performance”, "It helps me to know how fast I am”, "Something you could do at home” and "Good for people with weak arms".

Therapists answered yes to the initial question 'Has the device had any effect?' for 3 of the practice sessions, citing the participant's enjoyment in using the device, an increased motivation to try to reduce the latency between start of reach and start of grasp, that the feedback allowed the participant to measure his performance and motivated him to continue, highlighting for the participant the importance of hand opening, and an improved orientation of the head to the hand in one participant with neglect. Twice therapists answered negatively to this question, one stating that the particular participant's abilities were of too high a level and that it might be more effective in participants with more impairment, and the other noting no systematic changes in performance. When asked whether it had improved specific aspects of reach-to-grasp, 
three therapists answered that it had improved coordination and hand opening, and one that it improved the forward movement of the hand. One other positive effect was noted, which was that it "improved the quality of hand preparation for reach-to-grasp" (therapist of participant 4). The two therapists who answered negatively to the initial question on perceived usefulness answered similarly to these more specific questions.

All therapists thought it added extra value to the usual physiotherapy treatment, and two therapists added the following comments: "In general yes (it adds extra value), but this participant did not seem to find it useful” and "Alongside other treatment it may be helpful with carefully selected participants; it would be good to see if there is carry over into function/activities of daily living”.

\section{DISCUSSION}

Participants and therapists in user trials supported most aspects of the usability of GRASP, with the exception that three participants and one therapist thought the finger to thumb contact at the beginning of each trial could be improved. Two of these participants had a relatively low score of 3 on the arm section of the Rivermead Motor Assessment, and so this problem may be more prevalent with more impaired participants.

The opinions of the utility of GRASP were unanimously positive within the group answering the questionnaire. With the exception that one therapist thought the participant had difficulty in understanding what the device measures, all the users understood its purpose and thought it would fulfil this purpose. 
Several participants thought the feedback from the device was useful to improve coordination and hand opening in reach-to-grasp. Studies are needed to establish relative benefits of different types of feedback in stroke rehabilitation, including kinematic feedback ${ }^{24}$, so this study contributes in part to this process of investigation by providing a new means of giving kinematic feedback to participants.

Other reasons given related to the participant having improved attention to the task, either by focusing on the particular aspect to be improved, or attending more to the neglected hand. Devices such as GRASP could potentially have an important role in focusing attention, which is necessary for motor learning to occur ${ }^{25}$.

All participants thought it added value as an adjunct to the usual treatment. This is the usual role of feedback devices in stroke rehabilitation ${ }^{24}$ and GRASP is intended to be used as an adjunct to usual training. Both therapists and participants with stroke commented that it might have been more useful at a different stage in their recovery, or with a participant with different movement deficits. It is likely that there is both a lower and upper limit of suitability. Participants who are unable to oppose their finger and thumb and maintain that position will find the start position difficult. Participants who already grasp well may find that reach and hand opening are already well coordinated. However, both groups of participants might benefit from GRASP in that it may encourage them to move faster, which in itself is likely to lead to better coordination as there are higher correlations between the start of transport and grasp in fast movements ${ }^{3}$ 26. 
Two of the participants felt improvements might be greater with more practice. This is likely to be true as a greater intensity of upper limb practice has been shown to improve outcomes after stroke ${ }^{27}$. The most effective dose could be established by a dose-ranging study ${ }^{28}$. Intensity is related to the question of whether any improvement would last and transfer to everyday functional activity, raised by one of the therapists. The intensity of practice necessary with GRASP to produce a learning effect will need to be established.

\section{MULTIPLE BASELINE STATISTICAL ANALYSES}

\section{Participants}

Recruitment, setting and inclusion and exclusion criteria were the same as for user trials with an additional inclusion criteria being 'time between start of hand opening and start of hand transport > $60 \mathrm{~ms}$ '. Six stroke participants took part, none of whom had taken part in the user trials described in the previous section. The participant group consisted of 2 women and 4 men, with a mean age of 48.2 years (SD 14.6) and time since event causing brain damage was 22.1 months (SD 19.2). All CT scans reported parietal or middle cerebral artery involvement. None had receptive but two had expressive communication difficulties. The same clinical assessments were performed as for the user trials (Table 2). In summary, the group had a moderate degree of arm impairment, minor increases in muscle tone apart from participant 6, minor proprioception loss except for participant 3, minimal presence of neglect, optic ataxia, and impairments of spatial perception. 


\section{Design}

Six single case studies were conducted, each consisting of 40 reach-to-grasp trials. Each trial consisted of the task of reaching to grasp a jar. A multiple baseline across subjects design was the design of choice because the participants’ performance was not expected to revert to baseline after withdrawal of the intervention. The first series of trials was conducted with the device attached as a mechanism to report performance but without feedback being given to the participant. This first series of trials (further referred to as 'baseline') consisted of a randomly assigned length of 10, 15 or 20 repetitions. The baseline trials were followed by a series of intervention trials, which consisted of 30, 25 or 20 trials, depending on the length of the baseline phase. Two subjects were assigned a baseline of 10, two a baseline of 15 and two a baseline of 20 trials. Random assignment to length of baseline phase was used, using a computer generated sequence and opaque, sealed envelopes. These were opened by a person not involved as a study investigator.

\section{Procedure}

Two research physiotherapists who were not involved with the design of GRASP conducted these studies. The subject's task was to reach to grasp a glass jar (height 92mm, diameter $70 \mathrm{~mm}$, weight $230 \mathrm{~g}$ ), placed $30 \mathrm{~cm}$ anterior to the starting position of the hand, and move it onto a round mat (14 cm diameter) on the table, placed closer to the body (near edge of mat $5 \mathrm{~cm}$ in front of start position). The start position of the hand was directly in front of the elbow, and the jar was positioned directly ahead of the hand so that no change in shoulder rotation was normally required to grasp the jar. In the start position, the finger and thumb sensor were touching, the forearm was in mid-pronation, 
the elbow at approximately 100 degrees flexion, and the wrist rested on the metal plate, the edge of which was positioned at the edge of the table. The other arm rested in the participant's lap. Instructions to the subject were "reach forward, pick up the jar, and place it on the mat”.

The baseline phase was conducted, for the required number of trials, without feedback. Then the intervention_phase was conducted, with feedback to the participant. The following instructions were given to the subject at the beginning of the intervention phase:

"When reaching to grasp an object, the start of your hand opening and the start of your arm movement forwards , usually occur at the same time, i.e. they are synchronised. Some people with stroke have difficulty with this synchronisation. This machine is designed to give you feedback to make these two events more synchronised.

The display will tell you the time, in number of milliseconds, between the two events. Your aim is to try to make this number as small as possible, by thinking about making the start of the hand opening and the start of arm movement forward, happen at the same time”.

The subject then performed one trial with the less affected arm. Then the device was attached to the affected arm and the required number of trials were performed for the intervention phase. After each trial, the participant observed the result shown on the display, which indicated the time between the start of hand transport and start of grasp, in milliseconds, and which of these components started first. 


\section{Outcome measure}

The outcome measure was the time between start of hand transport and start of grasp, measured in milliseconds, by GRASP. This was recorded for each of the 40 trials of each of the participants.

\section{Data analysis}

Our data consist of the recorded time (in milliseconds) for each of the 240 trials (6 participants, 40 trials each). Additionally, for each trial we know whether it was part of the baseline phase or part of the intervention phase. Because the data are clustered by participant, each of whom embodies a set of unique characteristics that affect the dependent variable, it is necessary to control for the identity of the participant when analysing the variation in the 240 outcomes ${ }^{29}{ }^{30}$. We therefore conducted multilevel modelling (using the MLwiN 2.15 software). A random effects model, as presented below was specified with two levels - the response (time between start of transport and start of grasp), and the participant, with phase included as an explanatory variable:

$$
\begin{aligned}
& \text { Response }_{\mathrm{ij}}=\beta_{0 \mathrm{j}}+\beta_{1} \text { Phase }_{\mathrm{ij}}+e_{\mathrm{ij}} \\
& \beta_{0 \mathrm{j}}=\beta_{0}+u_{0 \mathrm{j}} \\
& u_{0 \mathrm{j}} \sim \mathrm{N}\left(0, \mathrm{o}^{2}{ }_{u 0}\right) \mathrm{o}^{2}{ }_{u 0} \\
& e_{\mathrm{ij}} \sim \mathrm{N}\left(0, \mathrm{o}^{2}{ }_{e}\right) \mathrm{o}^{2}{ }_{e}
\end{aligned}
$$

Where $\mathrm{i}=$ trial value (from 1 to 240 trials), $\mathrm{j}=$ participant, $\S_{0}$ is the (average) intercept, $\S_{0 \mathrm{j}}$ is the random intercept, $e=$ response residual, $u=$ participant-specific intercept residual, $\mathrm{N}=$ normal distribution and $\sigma^{2}=$ variance. Finally, the coefficient of substantive interest, $\aleph_{1}$, reflects the average difference between the values of the dependent variable in the base-line phase and the intervention phase while controlling for differences between 
participants. In other words, it is the estimate of the effect of the use of the device as a feedback mechanism for participant and therapist.

\section{RESULTS}

All participants completed 40 trials. Results are shown graphically in Figure 3. The estimates of the random effects model specified above are (with standard errors of estimates between brackets):

$$
\begin{aligned}
& \text { Response }_{\mathrm{ij}}=\S_{0 \mathrm{j}}+-235.56 \text { (56.33)Phase } \mathrm{P}_{\mathrm{ij}}+e_{\mathrm{ij}} \\
& \aleph_{0 j}=738.56(152.62)+u_{0 j} \\
& u_{0 \mathrm{j}} \sim \mathrm{N}\left(0,{\sigma^{2}}_{u 0}\right){\sigma^{2}}^{2}{ }_{u 0}=85207.97 \text { (51654.53) } \\
& e_{\mathrm{ij}} \sim \mathrm{N}\left(0, \mathrm{o}_{e}^{2}\right) \mathrm{ơ}_{e}^{2}=170952.93 \text { (15804.68) }
\end{aligned}
$$

The estimated decrease in the time between start of transport and start of grasp as a consequence of the intervention is highly significant $(\mathrm{p}<.0001)$, just over 235 ms. with a standard error of 56.33 .

INSERT FIGURE 3 ABOUT HERE

\section{DISCUSSION}

Participants were able to use the feedback to significantly reduce the time lag between the start of transport and the start of grasp. Thus GRASP could act as a useful adjunct to current physiotherapy intervention for coordination. 
A limitation of this study was the small sample size, however for a trial of a prototype this was considered adequate. Based on these findings a second prototype will be developed that is suitable for a larger range of motor impairment. The most effective dose may then be established via a dose-ranging study, followed by a controlled clinical trial designed to test whether using GRASP as an adjunct to reach-to-grasp training yields better outcomes than reach-to-grasp training alone.

\section{CONCLUSION}

Participants with stroke and therapists were mostly supportive of the usability, utitility and usefulness of GRASP. Feedback from GRASP resulted in a significant reduction in the time between onset of hand opening and arm movement forward. This pilot investigation of GRASP indicates that it is potentially beneficial as an adjunct to physiotherapy training of reach-to-grasp function after stroke.

\section{Acknowledgements}

This study was supported by a Mercia Spinner Pathfinder grant. 


\section{References}

1. Parker M, Wade DT, Hewer RL. Loss of arm function after stroke: measurement, frequency, and recovery. Int J Rehabil Med 1986;8:69-73.

2. Nakayama H, Jorgensen HS, Raaschou HO, Olsen TS. Recovery of upper extremity function in stroke patients: The Copenhagen Stroke study. Arch Phys Med Rehabil 1994;75:394-98.

3. VanVliet PM, Sheridan MR. Coordination between reaching and grasping in patients with hemiparesis and normal subjects. Arch Phys Med Rehabil 2007;88(10):1325-31.

4. Michaelsen SM, S Jacobs , A AR-B, Levin MF. Compensation for distal impairments of grasping in adults with hemiparesis. Exp Br Res 2004;157:162-73.

5. Jeannerod M. The timing of natural prehension movements. J Mot Beh1984;26(3):235-54.

6. Ungerleider LG, Mishkin M. Two cortical visual systems. In: Ingle DJ, Goodale MA, Mansfield RJW, editors. Analysis of visual behaviour. Cambridge, Massachusetts: MIT Press, 1982:549-86.

7. Goodale MA, Milner AD. Separate visual pathways for perception and action. Trends Neurosci 1992;15(1):20-25.

8. Jeannerod M, Biguer B. Visuomotor mechanisms in reaching within extrapersonal space. In: Ingle D, Goodale MA, Mansfield R, editors. Advances in the analysis of visual behaviour. Boston: MIT, 1982:387-409.

9. Gentilucci M, Castiello U, Corradin ML, Scarpa M, Umilta C, Rizzolati G. Influence of different types of grasping on transport component of prehension movements. Neuropsychologica 1991;29(5):361-78.

10. Castiello U, Bennett KMB, Stelmach GE. Reach to grasp: the natural response to perturbation of object size. Exp Br Res 1993;94:163-78. 
11. Wu CY, Chou SH, Kuo MY, Chen CL, Lu TW, Fu YC. Effects of object size on intralimb and interlimb coordination during a bimanual prehension task in patients with left cerebral vascular accidents. Motor Control 2008;12(4):296-310.

12. Rand MK, Shimansky Y, Stelmach GE. Effects of accuracy constraints on reach-to-grasp movements in cerebellar patients. Exp Br Res 2000;135:179-88.

13. Engardt M, Ribbe T, Olsson E. Vertical ground reaction force feedback to enhance stroke patients' symmetrical body-weight distribution while rising/sitting down. Scand J Rehabil Med1993;25:41-48.

14. Dursun E, Hamamci N, Donmez S, Tuzunalp O, Cakci A. Angular biofeedback device for sitting balance of stroke patients. Stroke 1996;27:1354-57.

15. Desmurget M, Epstein CM, Turner RS, Prablanc C, Alexander GE, Grafton ST. Role of the posterior parietal cortex in updating reaching movements to a visual target. Nat Neurosci 1999;2(6):563-67.

16. Binkofsky F, Dohle C, Posse S, Stephan KM, Hefter H, Seitz RJ, et al. Human anterior intrapareital area subserves prehension. A combined lesion and functional magnetic resonance imaging activation study. Neurology 1998;50:1253-59.

17. VanVliet PM. 2008. Feedback device. Patent application. WO2008117064-A1, 2 Oct

18. Virzi RA. Refining the test plate of usability evaluation: how many subjects is enough? . Human Factors 1992;34(2):457-68.

19. Lincoln NB, Leadbitter D. Assessment of motor function in stroke patients. Physiother 1979;65:48-51.

20. Bohannon RW, Smith MB. Interrater reliability of a Modified Ashworth Scale of muscle spasticity. Phys Ther 1987;2:206-07.

21. Rey A. Le test, de copie de figure complexe. Paris: Editions Centre de Psychologie Applique., 1959. 
22. Wimperris A. The Arm Position Matching test (APMT): The feasibility and precision of a new standardized method for quantifying arm position sense following stroke. Birmingham, School of Psychology 2007.

23. Perenin M-T, Vighetto A. Optic ataxia: a specific disruption in visuomotor mechanisms I. Different aspects of the deficit in reaching for objects. Brain 1988;111:643-74.

24. VanVliet PM, Wulf G. Extrinsic feedback for motor learning after stroke: what is the evidence? Dis Rehabil 2006;28(13-14):831-40.

25. Wulf G. Attention and motor skill learning: Human Kinetics, 2007.

26. Wallace SA, Weeks DL, Kelso JAS. Temporal constraints in reaching and grasping behaviour. Hum Mvt Sci 1990;9:69-93.

27. Kwakkel G, Wagenaar RC, Twisk JWR, Lankhorst GJ, Koetsier JC. Intensity of leg and arm training after primary middle-cerebral artery stroke: a randomised trial. Lancet 1999;354:191-96.

28. Piantadosi S, editor. Clinical trials: a methodological perspective. Hoboken ., New Jersey: John Wiley and Sons, 2005.

29. DiezRoux AV. Multilevel analysis inpublic health. Ann Rev Pub Health 2000;21:171-92.

30. DiezRoux AV. A glossary for multilevel analysis J Epidemiol Comm Health 2000;56:599-94. 


\section{Figure Legends}

Figure 1. GRASP ready to record a reaching movement

Figure 2. Results for baseline and intervention phases for participants 1 to 6 . Trial number is shown on the horizontal axis and time between start of hand transport and start of grasp (ms) is shown on the vertical axis. 
Table 1. Characteristics of participants in user trials

\begin{tabular}{|c|c|c|c|c|c|c|c|c|}
\hline Participant & CT scan & Time & Arm & Muscle & Neglect & Spatial & Optic & Proprioception \\
\hline no. & result & $\begin{array}{l}\text { since } \\
\text { stroke } \\
\text { (months) }\end{array}$ & $\begin{array}{l}\text { function } \\
*\end{array}$ & $\begin{array}{l}\text { tone } \\
\text { (wrist, } \\
\text { finger, } \\
\text { elbow) } \dagger\end{array}$ & $\S$ & perception & $\begin{array}{l}\text { ataxia } \\
П\end{array}$ & $\#$ \\
\hline 1 & $\begin{array}{l}\text { R parietal } \\
\text { infarct }\end{array}$ & 39 & 3 & $1,1,2$ & 55 & 36 & 40 & 1.47 \\
\hline 2 & $\begin{array}{l}\mathrm{R} \text { frontal and } \\
\text { posterior } \\
\text { parietal } \\
\text { lesion }\end{array}$ & 32 & 3 & $3,3,2$ & $* *$ & $* *$ & 38 & 1.77 \\
\hline 3 & $\begin{array}{l}\text { R low } \\
\text { attenuation } \\
\text { cerebral } \\
\text { hemisphere }\end{array}$ & 25 & 4 & $1,1,3$ & 38 & 15 & 20 & 0.98 \\
\hline 4 & $\begin{array}{l}\text { R middle } \\
\text { cerebral } \\
\text { artery infarct }\end{array}$ & 6 & 6 & $1,0,1$ & 25 & 14.5 & 9 & 1.34 \\
\hline 5 & $\begin{array}{l}\text { L } \\
\text { intracerebral } \\
\text { bleed }\end{array}$ & 6 & 11 & $0,0,0$ & 56 & 27 & 40 & 1.51 \\
\hline 6 & $\begin{array}{l}\text { R Middle } \\
\text { cererbral }\end{array}$ & 8 & 7 & $1,0,2$ & 55 & 36 & 35 & 2.12 \\
\hline
\end{tabular}




artery infarct
$\begin{array}{lllllll} & \\ \text { L fronto- } & 22 & 7 & 0 & * * & * * & * *\end{array}$ **
parietal
meningioma

- * Arm function (Rivermead Motor Assessment) maximum score, 15.

- $\quad$ † Muscle tone (Modified Ashworth Scale) score range: 0, no increase in muscle tone; 4, affected part rigid in flexion or extension.

- $\S$ Neglect (star cancellation) normal scoring range, 51-54; spatial perception (Rey figure copy) normal scoring range, 31-36.

- $\quad$ I optic ataxia: maximum score, 40.

- \# Proprioception: all scores shown are within range of normal population

- $\quad * *$ unable to test 
Table 2. Characteristics of participants in single case studies

\begin{tabular}{|c|c|c|c|c|c|c|c|c|}
\hline Participant & CT scan & Time & Arm & Muscle & Neglect & Spatial & Optic & Proprioception \\
\hline no. & result & $\begin{array}{l}\text { since } \\
\text { stroke } \\
\text { (months) }\end{array}$ & $\begin{array}{l}\text { function } \\
*\end{array}$ & $\begin{array}{l}\text { tone } \\
\text { (wrist, } \\
\text { finger, } \\
\text { elbow) † }\end{array}$ & $\S$ & perception & $\begin{array}{l}\text { ataxia } \\
П\end{array}$ & $\begin{array}{l}\text { (wrist, } \\
\text { finger, } \\
\text { elbow) \# }\end{array}$ \\
\hline 1 & $\begin{array}{l}\text { Right middle } \\
\text { cerebral } \\
\text { artery infarct }\end{array}$ & 14 & 10 & $1,0,1$ & 55 & 36 & 35 & $3,2,2$ \\
\hline 2 & $\begin{array}{l}\text { Right middle } \\
\text { cerebral } \\
\text { artery infarct, } \\
\text { particulary } \\
\text { parieto- } \\
\text { temporal } \\
\text { junction and } \\
\text { internal } \\
\text { capsule }\end{array}$ & 8 & 11 & $1,1,0$ & 54 & 27.5 & 35 & $2,0,2$ \\
\hline 3 & $\begin{array}{l}\text { Left fronto- } \\
\text { parietal } \\
\text { infract }\end{array}$ & 21 & 5 & $0,0,0$ & 54 & 24 & 39 & $2,3,3$ \\
\hline 4 & $\begin{array}{l}\text { Left Parietal } \\
\text { intracranial } \\
\text { haemorrhage }\end{array}$ & 17 & 12 & $0,0,1$ & 55 & 30 & 36 & $3,3,3$ \\
\hline
\end{tabular}


cerebral

infarct

cerebral

artery infarct

- * Arm function (Rivermead Motor Assessment) maximum score, 15.

- $\quad$ † Muscle tone (Modified Ashworth Scale) score range: 0, no increase in muscle tone; 4, affected part rigid in flexion or extension.

- $\S$ Neglect (star cancellation) normal scoring range, 51-54; spatial perception (Rey figure copy) normal scoring range, 31-36.

- $\quad$ I optic ataxia: maximum score, 40 .

- \# Proprioception (Nottingham Sensory Assessment) score range: 0, no appreciation of movement; 1 , appreciates movement takes place but direction incorrect; 2, mirror the direction of the test movement, but it inaccurate in its new position; 3 , Accurately mirrors the test movement to within $10^{\circ}$ of the new test position 


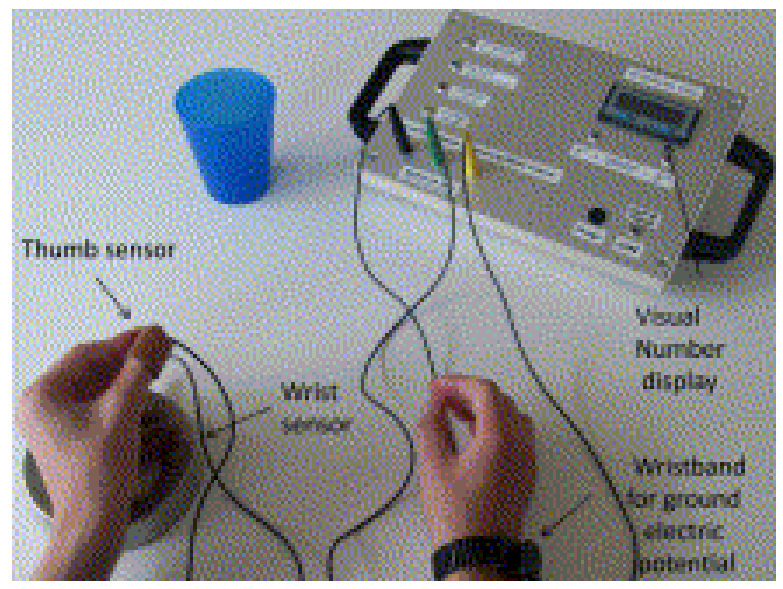

Figure 1. 


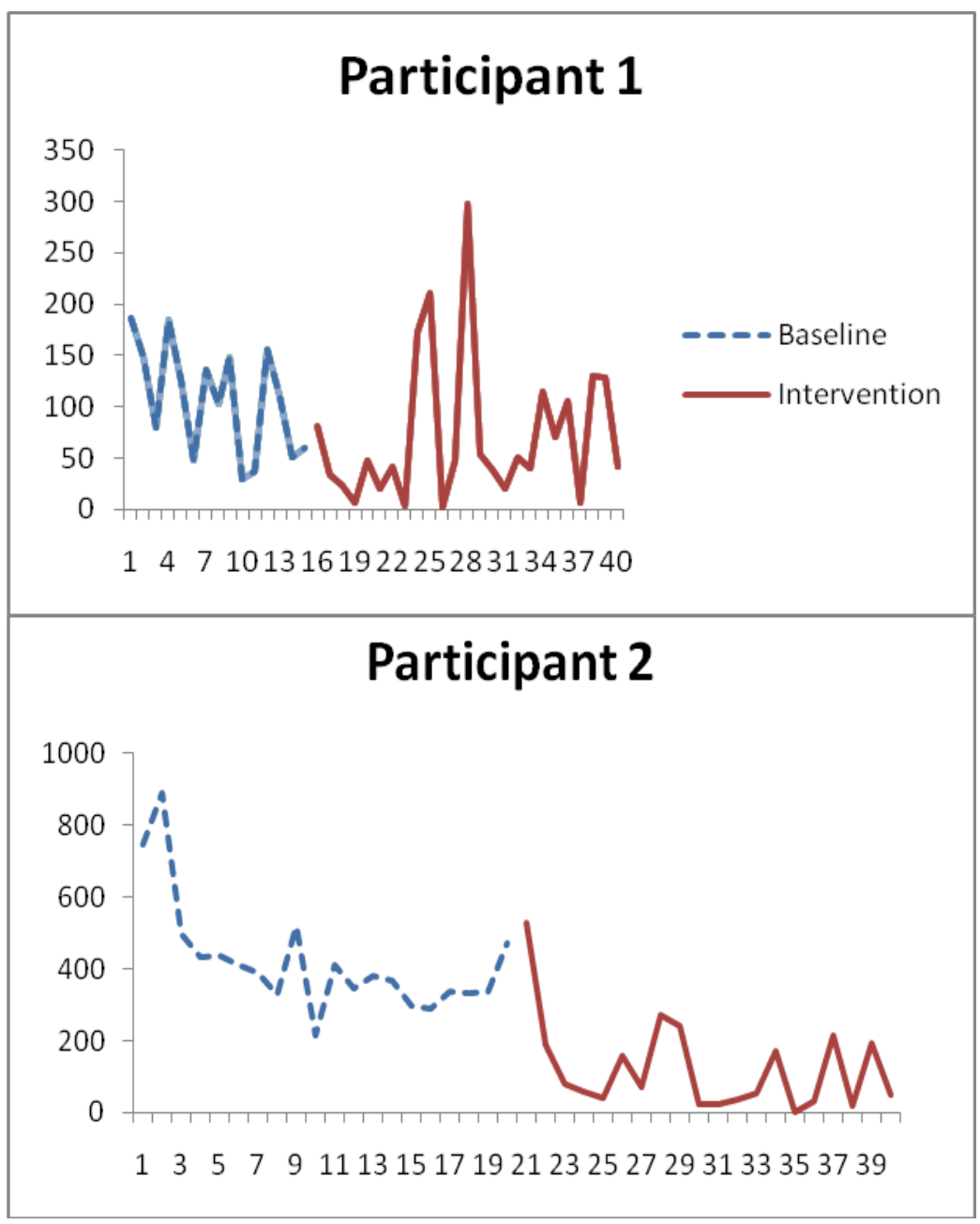




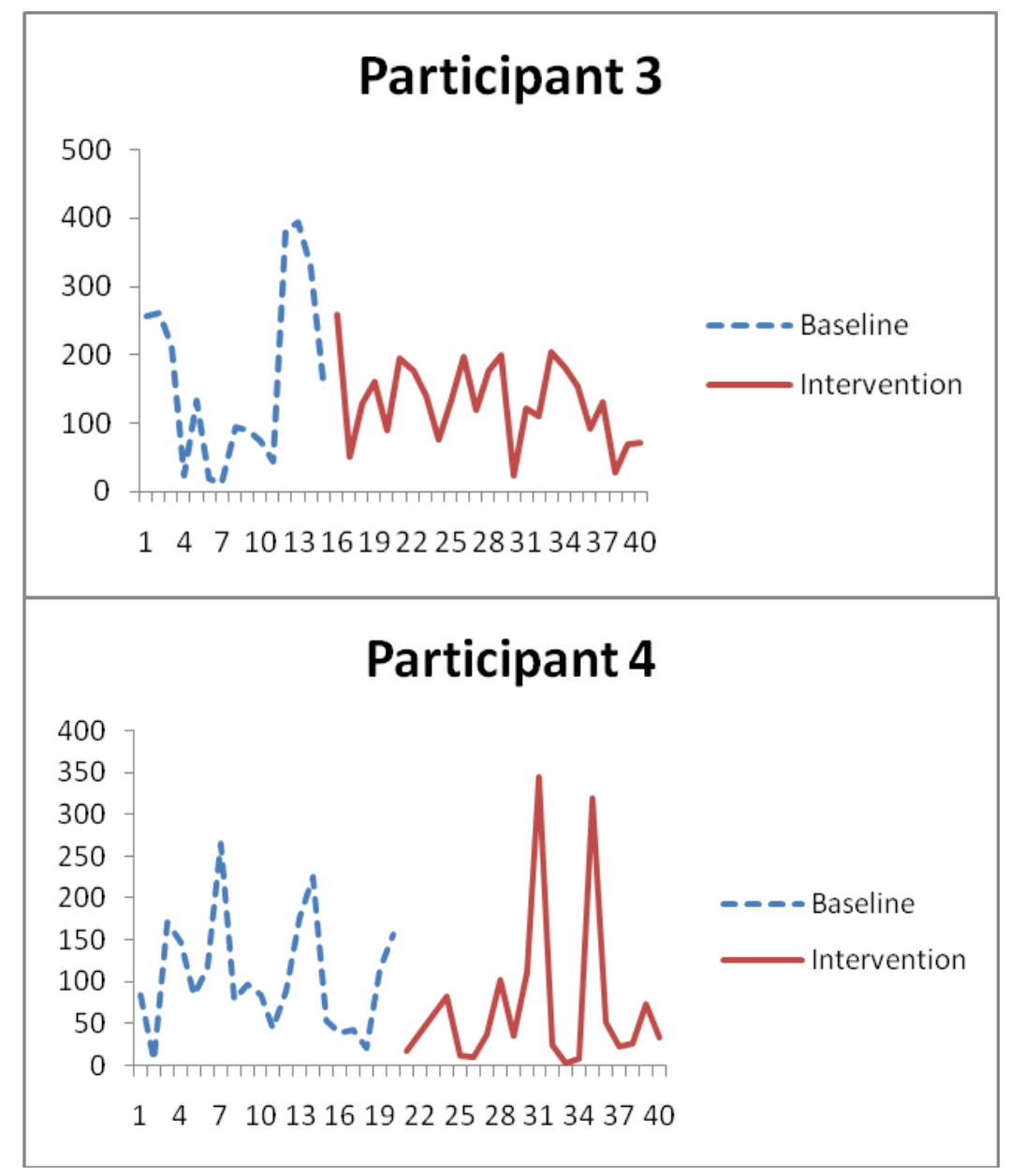




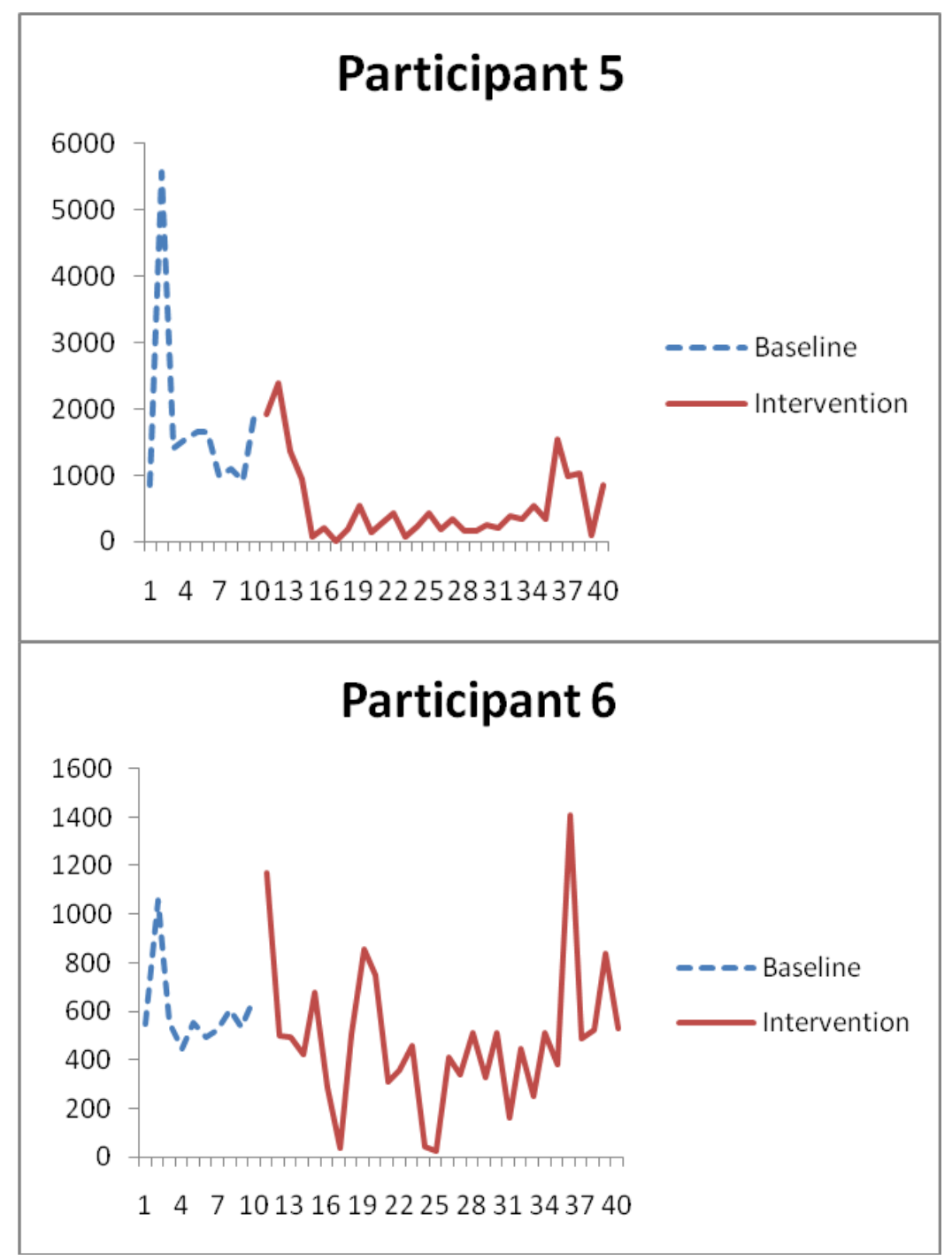

Figure 2. 